\title{
Unpacking physics representations: Towards an appreciation of disciplinary affordance
}

\author{
Tobias Fredlund, ${ }^{1, *}$ Cedric Linder, ${ }^{1,2}$ John Airey, ${ }^{1,3}$ and Anne Linder ${ }^{1}$ \\ ${ }^{1}$ Department of Physics and Astronomy, Uppsala University, Box 516, 75120 Uppsala, Sweden \\ ${ }^{2}$ Department of Physics, University of the Western Cape, Private Bag X17, Bellville, 7535 South Africa \\ ${ }^{3}$ Department of Languages, Linnaeus University, 39182 Kalmar, Sweden
}

(Received 7 July 2014; published 24 December 2014)

\begin{abstract}
This theoretical article problematizes the access to disciplinary knowledge that different physics representations have the possibility to provide; that is, their disciplinary affordances. It is argued that historically such access has become increasingly constrained for students as physics representations have been rationalized over time. Thus, the case is made that such rationalized representations, while powerful for communication from a disciplinary point of view, manifest as learning challenges for students. The proposal is illustrated using a vignette from a student discussion in the physics laboratory about circuit connections for an experimental investigation of the charging and discharging of a capacitor. It is concluded that in order for students to come to appreciate the disciplinary affordances of representations, more attention needs to be paid to their "unpacking." Building on this conclusion, two questions are proposed that teachers can ask themselves in order to begin to unpack the representations that they use in their teaching. The paper ends by proposing directions for future research in this area.
\end{abstract}

DOI: 10.1103/PhysRevSTPER.10.020129

PACS numbers: 01.40.Fk, 07.50.Ek

\section{INTRODUCTION}

One of the keys to successful physics learning is for students to come to appreciate the usefulness of a range of physics representations for both quantitative and qualitative understanding [1]. What is meant by representations here are semiotic resources, which are the actions, materials, and artifacts that get used for communicative purposes. In this sense, every representation used in physics is intended to provide access to certain parts of disciplinary knowledge $[2,3]$. Thus, all representations are partial in nature [4]. This partiality has two components. The first is an inherent partiality of the meaning that any single representation can convey $[2,4]$. The second is a partiality that arises from the creation of powerful communicative resources in the discipline of physics that has taken place through an evolutionary rationalization of the information and meaning that any given representation is intended to convey [5]. This theoretical article is about the teaching and learning challenges that arise from students experiencing this partiality of representations, where important physics aspects are not initially discernible. These issues are educationally important because what creates a powerful communicative system for physics at the same time manifests in the difficulties students experience in terms of becoming "fluent" [2] (p. 28) in the disciplinary-specific

\footnotetext{
*Corresponding author. tobias.fredlund@physics.uu.se

Published by the American Physical Society under the terms of the Creative Commons Attribution 3.0 License. Further distribution of this work must maintain attribution to the author(s) and the published article's title, journal citation, and DOI.
}

representations [2,6-23]. Theoretical details from the literature, together with the concept of disciplinary affordance $[11,12]$, are used to underpin a case that physics representations need to be "unpacked" for students. A vignette from the student laboratory is used to illustrate the depth of the problem and a discussion of the rationalization of representations is used to offer a guiding conceptual framework for thinking about these challenges in physics.

\section{THE POWER OF REPRESENTATIONS FOR PHYSICS}

\section{A. The disciplinary affordance of a representation}

The function that a given representation fills in physics in terms of potentially providing access to disciplinary knowledge has been characterized as the disciplinary affordance of that representation [11,12]. Compare, for example, solving a mechanics problem using a free-body diagram with using an equation such as Newton's second law. These representations are both similar and different in terms of the access to disciplinary knowledge that they provide. Which particular representation is the most appropriate for a given task depends partly on those aspects of the situation that are disciplinary relevant. From a physics point of view, the free-body diagram captures important aspects of a mechanics situation. However, in order to calculate a numerical answer, certain pieces of information need be "converted" into an equation for "treatment" [24,25]. An experienced physicist will choose the most appropriate representation according to the task at hand-in other words, the representation with the most appropriate disciplinary affordance. An illustrative example of this situation is provided by Van Heuvelen [1]; see Fig. 1. 
(a) Words

A parachutist whose parachute did not open landed in a snow bank and stopped after sinking $1.0 \mathrm{~m}$ into the snow. Just before hitting the snow, the person was falling at a speed of $54 \mathrm{~m} / \mathrm{s}$. Determine the average force of the snow on the $80-\mathrm{kg}$ person while sinking into the snow.

(b) Pictorial Representation

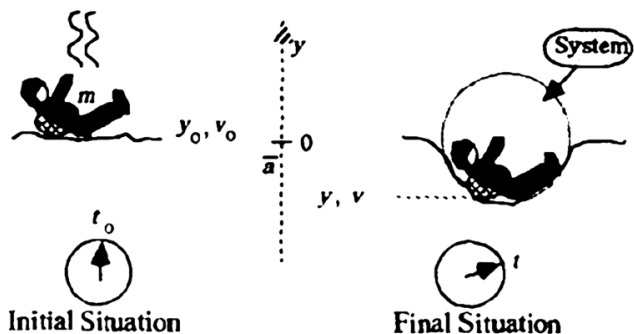

(c) Physical Representation
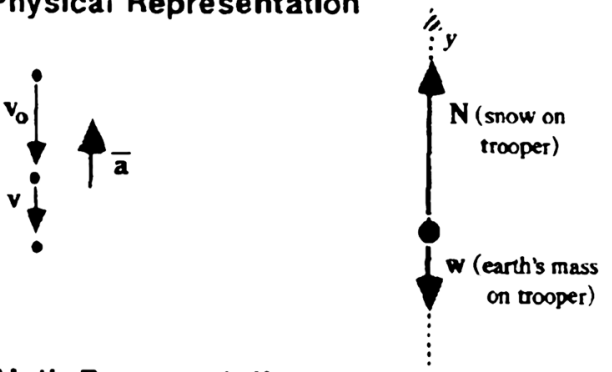

(d) Math Representation

$$
2 \bar{a}\left(y-y_{0}\right)=v^{2}-v_{0}^{2} \quad \sum F_{y}=N-w=m \bar{a}
$$

FIG. 1. An example of the need for different representations with different disciplinary affordances for solving a physics problem [1]. [A. Van Heuvelen, Learning to think like a physicist: A review of research-based instructional strategies, Am. J. Phys. 59, 891 (1991), (p. 892). Copyright 1991, American Association of Physics Teachers].

The pieces of information that are presented by different representations often overlap partly or entirely [2], for example, the magnitude of a force given by a number and given in terms of the length of an arrow that is drawn to scale. In other cases pieces of information are presented by representations with unique disciplinary affordances. Compare, for example, the equation $F=m g$ (which makes possible the calculation of a numerical value of the gravitational force acting on a close-to-Earth object with known mass) with $F_{g}=G m_{1} m_{2} / r^{2}$, which makes possible this calculation at any distance $r$ between the centers of masses of two objects with known masses. This "division of labor" between representations often makes the disciplinary affordance of constellations of representations more powerful than that of an individual representation; as McDermott [15] points out, "different representations emphasize different aspects of a concept" (p. 19). Airey and
Linder [2] illustrate this using a hypothetical constellation of representations that is needed in order to experience an object of learning in a disciplinary way. Such a constellation of representations can be said to have a collective disciplinary affordance [16], and is necessary (but perhaps not sufficient) to access all facets of a particular disciplinary way of knowing. A constellation of representations usually also facilitates the extension of meaning [26], and the reduction or removal of ambiguous pieces of meaning $[27,28]$.

\section{B. "Rationalizing" communication: The increasing partiality of representations}

There is a general tendency for representations to evolve by "packaging the knowledge that has developed over a long series of preceding arguments" [5] (p. 131). The history of physics provides ample evidence of how the inherent partiality of representations [4] has increased through an on-going process of rationalization. For an overt example, consider Einstein's [29] introduction of the meaning of the summation sign being incorporated into convention:

"A glance at the equations of this paragraph shows that there is always a summation with respect to the indices which occur twice under a sign of summation (e.g., the index $\nu$ in... $\left.\left[d x_{\sigma}^{\prime}=\sum_{\nu} \frac{\partial x_{\sigma}^{\prime}}{\partial x_{\nu}} d x_{\nu}\right]\right)$, and only with respect to indices which occur twice. It is therefore possible, without loss of clearness, to omit the sign of summation. In its place we introduce the convention:-If an index occurs twice in one term of an expression, it is always to be summed unless the contrary is expressly stated" [30] (p. 121-122).

What Einstein meant here was that-providing users have achieved "fluency" with the summation representation-it suffices to write $a_{i} x_{i}$ as a rationalization of $\sum_{i} a_{i} x_{i}$.

The rationalization of representations has been studied by linguists and multimodal discourse analysts. Their work describes how rationalization takes place across the full text of physics communication, that is, all forms of representations, including language, mathematics, and diagrams [26,31-34]. In order to offer a guiding conceptual framework for thinking about the rationalization of representations in physics, these are given consideration starting with the rationalization of scientific language [35-37], which involves a number of processes. One of the processes contributing to this rationalization is the conversion of a verb into a noun through nominalization [38]. For a physics example, consider the verb "conserve." The nominalized form of this verb is "conservation." The benefit for physics of using the latter form is that the meaning of conservation can be extended in ways that facilitate further classification of conservation to create new associated concepts, such as conservation of energy, conservation of momentum, etc. 
The importance for students to purposefully begin to use nominalized terms in their learning has recently started to be explored [39].

Nominalization often takes place in an integrated manner with other rationalizing processes, notably what in linguistics is characterized as rankshift [40]. Rankshift transforms a more complex unit of language to a less complex one, for example, the transformation of a clause (which in written language is the smallest kind of sentence-containing at least one verb) into a noun or a "nominal group" (which fills the role of a noun). The newly formed word (or group) can then be "embedded" in new clauses to efficiently construct meanings that could not otherwise be so efficiently constructed. For example, the clause "kinetic energy... is conserved" [41] (p. 300) can be rankshifted to form the nominal group "conservation of kinetic energy." This nominal group can then be used to fill the function of a noun in a sentence such as "...this approach is needed to avoid violation of the conservation of kinetic energy..." [42] (p. 71, italics ours). This example also illustrates how the rankshift or nominalization process can be iterated, whereby a nominal group, like "conservation of kinetic energy" mentioned above, can become embedded in an even larger nominal group such as, in the exemplar sentence just given, "violation of the conservation of kinetic energy."

A distinction can be made between the different examples above. In the example from Einstein, the rationalization is a manifestation of an economy of communication that characterizes physicists' representational practices. In the examples from language given later, the rationalization, in the form of nominalization and rankshift, is a process that contributes to extending the meanings [also called a "semogenic process" [43] (p. 17)] that can be made with language in scientific communication. (For further discussion of the role of nominalization in physics education, see Ref. [44].) We propose that these two kinds of rationalization are positioned at opposite poles of a continuum of various rationalization types, between which it may be difficult to differentiate.

For a mathematics example of a rankshiftlike rationalization that is relevant to physics, consider the common physics practice of writing the vector components $F_{x} \mathbf{i}+$ $F_{y} \mathbf{j}+F_{z} \mathbf{k}$ simply as $\boldsymbol{F}$. Doing so enables the composite force vector to be represented in a general way facilitating its use in more complicated equations. Often this practice also makes the notation less cumbersome, for example, when various operators, such as differential and integral operators, act on the mathematical expression of the force at hand. Consider, for example, the work done by the force $\boldsymbol{F}$ acting on an object moving along a trajectory $C$, which, in a kind of rankshifted form, becomes $\int_{C} \boldsymbol{F} d \boldsymbol{r}$. Here, the formulation can be seen to be independent both of the parametrization of the problem and of the choice of coordinate system. In this way, the rankshifted or rationalized notation is extremely useful and can then be adapted to the particular circumstances at hand in various situations.

For the case of diagrams, consider the rationalization that occurs during the creation of free-body diagrams. An example can be seen in Fig. 1. Here, the "parachutist" from the written text is first drawn in a two-dimensional sketch before being rationalized to a dot in the final diagram.

It should be noted that in both of the above examples, the rationalization process has led to a more generalized representation. However, from a student point of view, using such generalized representations is even more problematic since it calls for an in-depth understanding of how these representations relate to the particular situations at hand. This understanding is something that research has shown only develops over an extended period of time $[17,45,46]$.

\section{EDUCATIONAL CHALLENGES EMERGING FROM REPRESENTATIONAL PARTIALITY}

\section{A. The appreciation of disciplinary affordances of representations: A learning challenge}

While the rationalization of physics representations creates a powerful communicative system for physics, it manifests as a learning challenge for students who cannot discern important physics aspects that lie beyond what is directly discernible in the representations that are used in educational settings. Halliday [38] points out that, in language, a consequence of nominalization-which we have described as a constituent process in the rationalization of language,

"is not loss of semantic distinction but ambiguity: the different possible meanings are still discrete. This mayindeed it often does-create problems for the learner, who has to guess right, often without realising there is more than one possible interpretation" ( $p$. 228).

This means that although information may not be directly discernible when a rationalized wording is used, the wording still has a particular intended meaning. Thus, the recipient of the wording may need to infer extra information in order for the intended meaning to be appreciated [43]. For example, with respect to the sentence "Lung cancer death rates are clearly associated with increased smoking," Halliday [47] asks

"What is lung cancer death rates: how quickly lungs die from cancer, how many people die from cancer of the lung, or how quickly people die if they have it? What is increased smoking: more people smoke, or people smoke more?" (p. 74)

Rankshifting and nominalization may thus result in ambiguous messages for noninitiated readers. In our case, 
we argue that the more a representation has been subject to rationalization, enhancing its usefulness to physicists, the more inaccessible these parts of the information potentially become to students.

\section{B. The appreciation of disciplinary affordances of representations: A teaching challenge}

Despite extensive research showing that physics students experience many difficulties with representations (well documented in the field), teachers often do not easily appreciate the full extent of these difficulties. For example, Meltzer [10] notes that "the instructor's view of the ease or difficulty of a particular representation in a particular context might not match the views of a large proportion of students" (p. 473). This inability of physics teachers to judge the difficulties that a given representation may pose for students has also been reported by other researchers $[15,48,49]$. In this respect, Northedge [50] claims that "[university teachers'] thoughts are so deeply rooted in specialist discourse that they are unaware that meanings that they take for granted are simply not construable from outside the discourse" (p. 256). In other words, in many cases teachers have become so familiar with the disciplinary representations that they use that they no longer "notice" the learning hurdles involved in interpreting the intended meaning of those representations. Teachers may expect students to quickly become as fluent as they themselves are, and to appreciate the disciplinary affordances of the physics representations that they use. However, research shows that student fluency with representations is something that often needs an extended period of time to develop [17,51,52].

The inverse relationship between the representations that make learning possible and the powerful rationalized representations used in the discipline creates challenges for the teaching and learning of physics. These challenges result from the use of rationalized representations in the intense flow of communication between teachers and students.

\section{Towards meeting the challenges: Unpacking representations}

As we have pointed out, the general direction of the ongoing process of rationalization means that much of the intended meaning of representations is not immediately discernible. The challenge for the teachers then becomes to "reverse" the processes that contribute to this rationalization, e.g., through a kind of "reverse rankshift" [53] (p. 92), denominalization [44], and "derationalization." Although none of these reversed processes are "natural," and therefore not described in any detail in the literature, they have been collectively known as unpacking [54] (cf. also Lemke's [32] "expansion"). For the purposes of this article, we are going to use this same term-unpacking-to capture the idea of going back through a process of rationalization (derationalization) in order for students to come to "see" the parts of intended meaning that are not directly discernible in the representation.

The unpacking approach to addressing the teaching and learning challenges that we have described is illustrated by this quote from Feynman, Leighton, and Sands [55], who give consideration to the challenges that students face when encountering a new problem involving the divergence of a vector:

“...if you are trying to calculate the divergence of a vector, instead of just looking at $\nabla \cdot \boldsymbol{E}$ and wondering what it is, don't forget that it can always be spread out as

$$
\frac{\partial E_{x}}{\partial x}+\frac{\partial E_{y}}{\partial y}+\frac{\partial E_{z}}{\partial z}
$$

If you can then work out the $x, y$, and $z$ components of the electric field and differentiate them, you will have the divergence. There often seems to be a feeling that there is something inelegant-some kind of defeat involvedin writing out the components; that somehow there ought always to be a way to do everything with the vector operators. There is often no advantage to it. The first time we encounter a particular kind of problem, it usually helps to write out the components to be sure we understand what is going on. There is nothing inelegant about putting numbers into equations, and nothing inelegant about substituting the derivatives for the fancy symbols. In fact, there is often a certain cleverness in doing just that. Of course when you publish a paper in a professional journal it will look better-and be more easily understood - if you can write everything in vector form. Besides, it saves print” (p. 6-4).

The central parts of our argument are (i) that rationalization of a representation contributes to the creation of powerful communicative resources for physics, and (ii) that the educational downside of such rationalization of representations is that pieces of information become no longer directly discernible.

Based on the theoretical background given in this article, we propose that the unpacking of representations constitutes an important aspect of (experientially) coming to appreciate the disciplinary affordances of representations. Such "unpacking" of a representation would make discernible those pieces of information that were initially inaccessible to students, due to the overt or covert rationalization that has occurred.

In the following vignette we will illustrate important aspects of our proposal regarding how representational rationalization that is powerful for physicists and engineers at the same time involves learning challenges for students and undermines their discernment of relevant physics aspects. 


\section{AN ILLUSTRATIVE VIGNETTE \\ FROM THE STUDENT LABORATORY DEALING WITH AN $R C$ CIRCUIT}

Physics education research literature has shown that students typically find electric circuits a challenging part of their physics learning experience [52-60]. In the following illustrative vignette, students taking an introductory university course on electromagnetism are working with electric circuits in the student laboratory. As indicated by discussions we have had with laboratory assistants, students in this part of the course invariably experience difficulties connecting the electric circuits appropriately.

\section{A. The laboratory exercise}

The data on which this vignette is based were collected when a group of three students engaged in a laboratory exercise to experimentally study the charging and discharging of a capacitor using an oscilloscope (see the laboratory instruction in the Appendix). The students' work was video recorded with a hand-held camera, and in order to get better sound quality, the audio data were collected using a separate microphone. The audio data were transcribed verbatim, and the different ways the students connected the oscilloscope and a signal generator into their circuit were carefully reconstructed in the laboratory. Photographs were taken of both the circuit reconstructions and of the oscilloscope screen output for each of the reconstructed connections (comparisons were made with the video data to make sure that the outputs we obtained accurately matched those of the students). The relationships between the students' connections and a given circuit diagram (Fig. 2) were further documented by inserting red and black colored dots into the diagram to represent the red and black colored connectors that were used [61]. The audio data, the video data (giving due consideration to any pointing gestures that were captured in the video), and the matched reconstructions were simultaneously brought together to generate our understanding of the sequence of events [62-66].

The exercise began with the students choosing an appropriate capacitor and resistor and connecting them

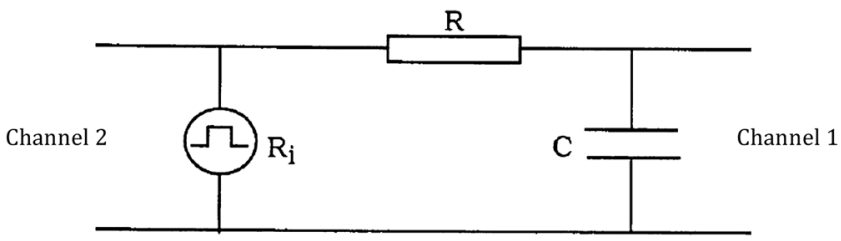

FIG. 2. The $R C$ circuit diagram given in the laboratory exercise instruction featuring a function generator $\left(R_{i}\right)$, the two channels of an oscilloscope, a capacitor $(C)$, and a resistor $(R)$. (Note that resistors are sometimes drawn as a rectangle in Swedish physics textbooks.) Of this information only the labeling of the function generator was explained in the laboratory instructions. to a function generator and an oscilloscope according to the electric circuit diagram in Fig. 2. An appropriate frequency of a prescribed square wave from the function generator also had to be chosen, so that a sufficient part of the charging and discharging process could be observed on the oscilloscope. The voltages across the function generator output and across the capacitor were to be measured using two different oscilloscope channels.

The electric circuit schematically depicted in the circuit diagram in Fig. 2 is a standard $R C$ circuit: standing for a resistor-capacitor circuit. The circuit diagram itself is a typical representational format that is often used in electronics. However, in order to assemble the circuit appropriately in the laboratory, students need to take into consideration a number of aspects that are not directly discernible in the circuit diagram. For example, there is no information in the diagram as to which function generator or oscilloscope to use, and why. Also, the circuit diagram does not distinguish between the different cables that could be used. Instead, it is actually the equipment available in the laboratory that helps to reduce the options that the students have to choose from.

For oscilloscopes, coaxial cables are the preferred cable choice. This is because they are shielded, which makes them ideal for transporting a broad range of frequency signals (they have two separated conducting parts; an outer "shield" and an inner "core"). Coaxial cables generally have Bayonet Neill-Concelman (BNC) connectors at both ends. In some cases the coaxial cables have one end split into two separate parts (see Fig. 3). Although both of the mentioned types of coaxial cables were available in the laboratory, it was this second type of cable that was required in this exercise. This is because the available function generators and oscilloscopes needed cables to have BNC connectors whereas the capacitors and resistors required banana plugs. The split ends were colored red and black. By convention, red is connected to the inner conductor of the coaxial cable, which carries the signal, while black is connected to the common ground potential

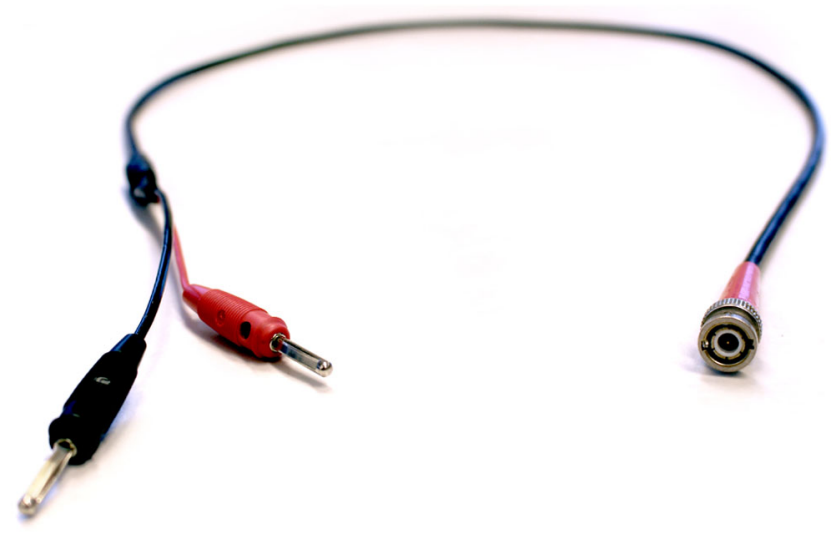

FIG. 3. A coaxial cable with the black and red colored banana plugs on the left and the BNC connector on the right. 
carried by the outer shield. Thus the signal is measured with reference to this common ground.

There are several aspects related to making the appropriate connections that the given circuit diagram (Fig. 2) does not explicitly present. For example, the location and the role of a circuit ground. The function of a circuit ground is to make sure that all devices that carry the same reference potential are connected to the same point in the circuit. In this way any signals (e.g., for the voltage input from the function generator and voltage output as measured over the capacitor) can be measured relative to this potential using the oscilloscope. Here, the outer shield of the coaxial cable (in our case, the black colored banana plug) fills the function of connecting an apparatus to the point of common "ground potential." The inner core of the cable carries the signal relative to this ground potential. Therefore, in this illustrative vignette, both channels of the oscilloscope and the signal generator would have to be connected to the circuit ground with the coaxial cables' black colored banana plugs. However, the location of this ground potential is, as mentioned, not indicated explicitly in the circuit diagram in Fig. 2. In other words, the partiality of this representation does not allow it to provide "novices" access to this information. In a sense, this information has been rationalized away. Once a choice has been made regarding how to position the circuit ground, the signal cable from each device can be connected to an appropriate position as per the circuit diagram.

In sum, the schematic circuit diagram given in the instructions for the laboratory exercise does not provide any details of the cables and measurement equipment to be used, nor does it suggest where the circuit ground should be located (this information was not indicated anywhere else in the immediate laboratory environment). In contrast to being "salient features" [67] (p. 4), these features have been rationalized away, which (at some level of learning) renders the circuit diagram ambiguous. From a disciplinary insider's point of view this rationalization creates powerful meaning sharing with the minimum of "input." However, for a successful outcome of this laboratory exercise, students need to be aware of the detailed relationships between the components involved in the circuit and how this relates to the circuit diagram representation. (It should be noted here that for most students taking the course the fundamental conventions for connecting a circuit, including how to connect the oscilloscope and the function generator, was part of the curriculum of an earlier course on measurement techniques.)

We will now present excerpts from the data where the three students Ben, George, and Will (pseudonyms) attempt to (a) connect the circuit and (b) get the appropriate signal to show on the oscilloscope screen. These excerpts present the sequential development of how the students connected their circuit. The video data will be presented in a form of "multimodal transcription" [68,69]] that involves the verbatim transcriptions and the situational illustrations of reconstructions of the laboratory setup.

\section{B. Carrying out the laboratory exercise \\ 1. Connecting the circuit}

The students first selected the equipment that they needed in order to connect the circuit. Two of the students, George and Ben, started by connecting channel 1 and 2 of the oscilloscope, and the function generator, to a resistor and a capacitor. There was some initial confusion regarding which of the red or black colored banana plugs should be on which side of the capacitor as illustrated by Ben's comment "if it matters...." The students' first attempt at connecting the circuit is shown in Fig. 4, and the resulting image on the oscilloscope screen can be seen in Table I (a). Notice that although this circuit is incorrect, the reasons for this incorrectness cannot be seen in the circuit diagram given in the laboratory instructions.

The students' circuit in Fig. 4 shows that the signal from the function generator has been connected to the reference potential of channel 1 . It appeared as if the students were treating the red or black colored banana plugs as if they were connecting a voltmeter. Voltmeters are not connected to a common reference potential, but should be connected across the component, i.e., to each end of the component across which one intends to determine the voltage.

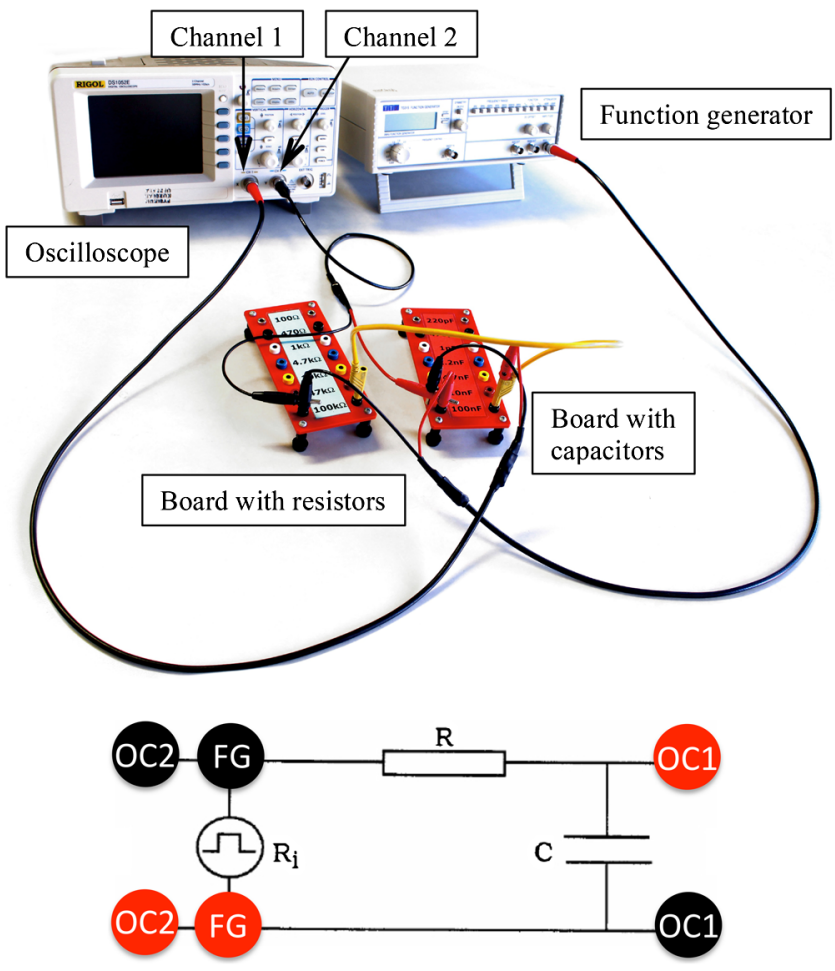

FIG. 4. A pictorial and a diagrammatic representation of the students' first attempt at connecting the circuit. FG refers to the function generator and OC1 and OC2 refer to the oscilloscope's channel 1 and channel 2, respectively. 
TABLE I. Summary of the illustrative vignette showing the sequence of connections and reconnections of the circuit that the students carried out and the oscilloscope images obtained at each stage. The signal from the function generator and the capacitor are shown in blue and yellow, respectively.

Description $\quad$ Circuit connection Image on the oscilloscope screen

(a) The students' first connection

(b) The students' simplified connection

(c) The circuit after the TA's first intervention
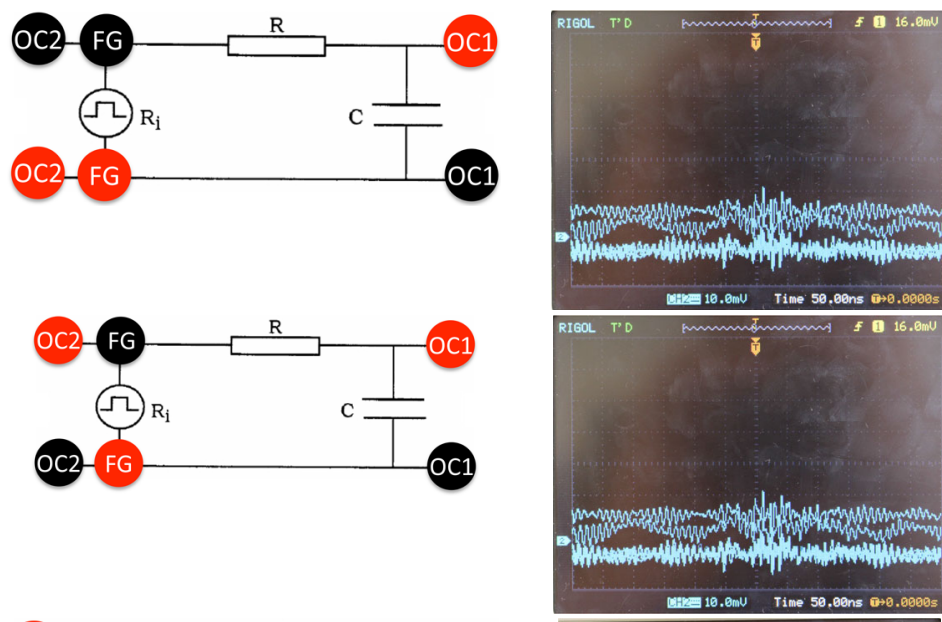

(d) The same circuit after having increased the frequency
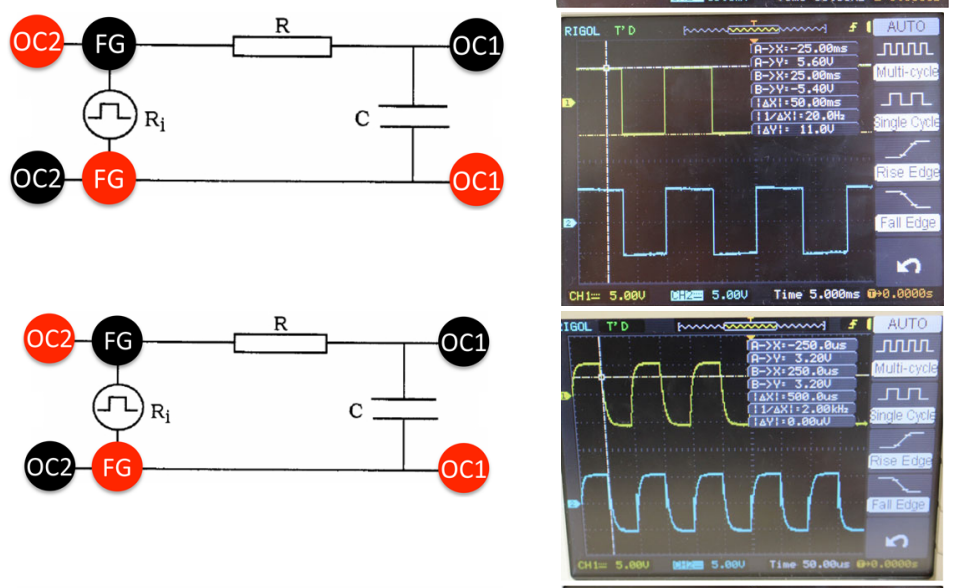

(e) The circuit after the TA's second intervention
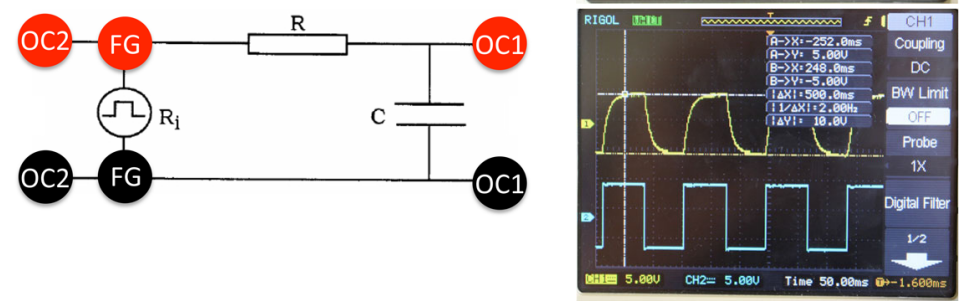

However, voltmeters are not suitable for showing a visualization of rapidly varying voltages and therefore the oscilloscope was used for this laboratory exercise.

\section{Simplifying the circuit}

Having completed this first attempt to connect the circuit, the students struggled with getting the oscilloscope screen to show anything meaningful by, for example, trying different frequencies of the square wave input signal. This prompted Will to ask "Have we even connected it correctly?" while carefully examining their circuit. When the input signal did not show on the oscilloscope screen, they attempted to simplify their connections by connecting the function generator directly to the oscilloscope's channel 2 with a coaxial cable that had BNC connectors at both ends. They managed this by getting a BNC $\mathrm{T}$ connector (see Fig. 5) to simultaneously connect the function generator to the circuit with a split-end coaxial cable. The assumption being that the correct connections would be built into the two BNC connectors by default. This was in fact the case and the cable substitution reversed the polarity of the connection (see Fig. 6). Note, however, that the students could not observe this reversal since they no longer had red and black colored banana plugs to connect. Compounding this problem, the new circuit did not change the image on 


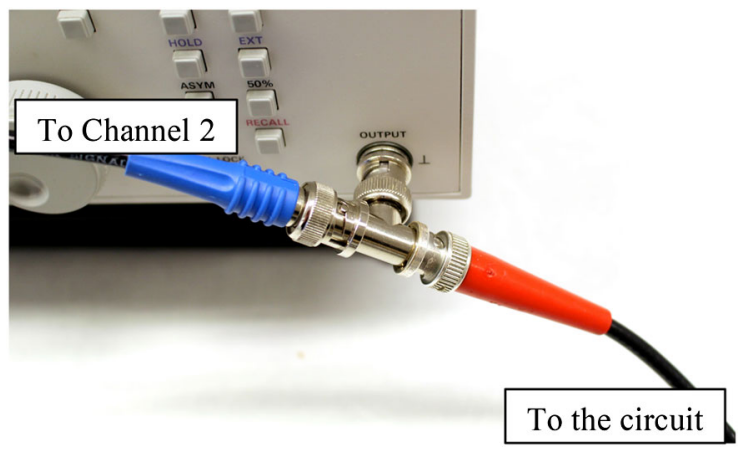

FIG. 5. The T connector that was used to connect the function generator to the oscilloscope (channel 2) and to the circuit.

the oscilloscope either [see Table I (b)]. This was due to the students' inappropriate oscilloscope settings.

\section{Troubleshooting the circuit}

Still not getting a good image on the oscilloscope screen, the students asked the teaching assistant (TA) for help. While waiting for the TA to arrive, Will and Ben had the following conversation:

Will: It is connected properly, right?

Ben: Yes, I think so.
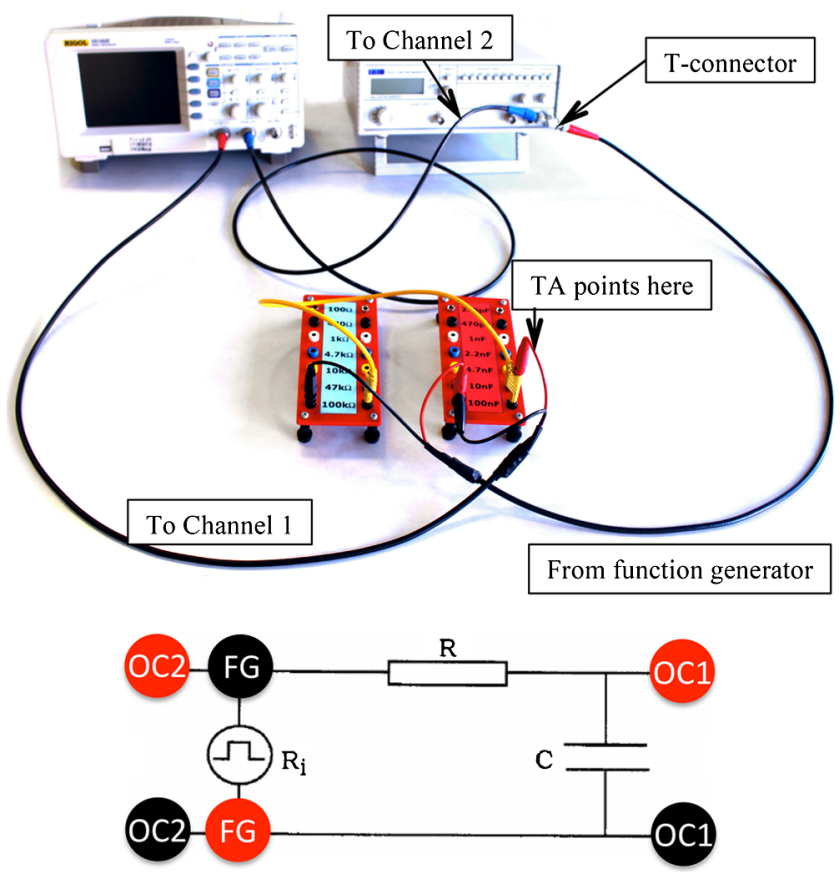

FIG. 6. A pictorial and a diagrammatic representation of the students' circuit after they had connected the oscilloscope's channel 2 directly to the function generator. FG refers to the function generator and OC1 and OC2 refer to the oscilloscope's channel 1 and channel 2, respectively. As pointed out earlier, the OC2 connections took place by default through the use of the BNC T connector (see Fig. 5).
Will: It's the capacitor, the resistor, then we complete it, and then...

When the TA arrived, the following conversation took place.

TA: What's the problem?

Ben: First we would like to verify that we connected this correctly.

TA: Let me see.... Yes, now I see. I see one thing that is odd here. Ehm, it's like this, these [holding the cables entering the circuit from the function generator], have a grounding cable and a signal cable. The grounding in function generators and the oscilloscope...

Ben: They should be the same.

TA: [Still holding the cables entering the circuit from the function generator], ... it is the same. So, in principle, what you do here is that you take the signal from the function generator and you run it directly to the ground. Then nothing happens. There is no current in the rest of the circuit. So you have to start by changing, changing their places. Then I suppose it is easiest to change the polarity of this [pointing at the red colored banana plug going to channel 1; see Fig. 6].

Following their understanding of the TA's advice, the students swapped the places of the red and black colored banana plugs to channel 1 across the capacitor, rendering the circuit connected as in Fig. 7. Both the function generator and channel 1 were now connected to the same place in the circuit with red banana plugs. After this the students were able to get readable signals to show on the oscilloscope screen [see Table I (c)].

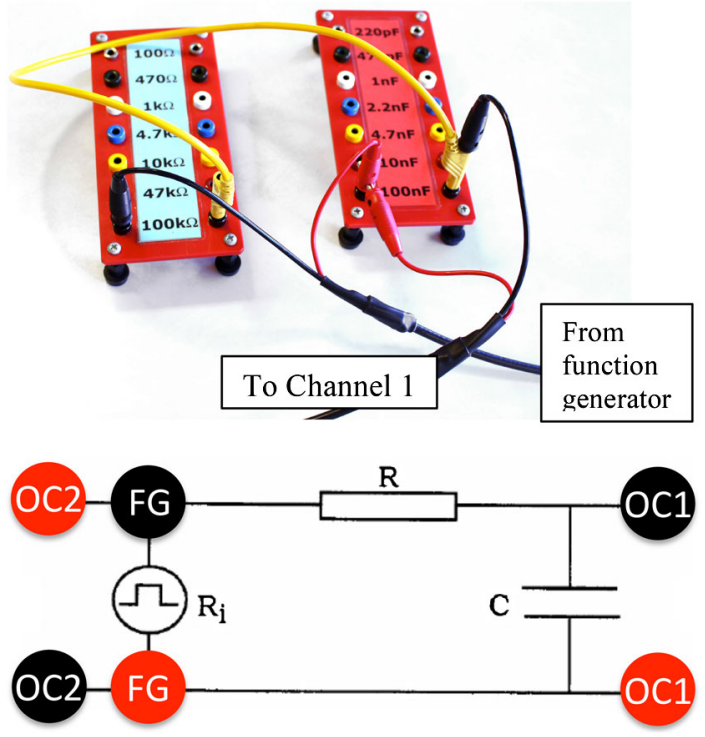

FIG. 7. A pictorial and a diagrammatic representation of the students' circuit after it had been corrected according to the TA's advice. Both "signal ends" of the cables were then connected to the same (equivalent) point in the circuit. FG refers to the function generator and OC1 and OC2 refer to the oscilloscope's channel 1 and channel 2 , respectively. 


\section{Correcting the circuit}

The signals from the two channels still did not look the way the students expected them to-they looked identical. Ben, referring to the images on the oscilloscope, said,

Ben: But, they are exactly the same.

TA: Mm. That means that there is not so much going on in the circuit. Why does it not? We can try either to change the capacitance, or we can change the frequency, and see if something happens.

After trying to change both the capacitance and the frequency, the two signals (input voltage and output voltage) still had identical forms on the oscilloscope screen [see Table I (d)]. The TA who had been observing this started to work on the circuit himself:

TA: We can try this. This can be... We'll let the signal go the other way so to speak-it can make a difference. Like so.

After the TA had completed the needed changes to the circuit; swapping the places of the red and black colored banana plugs, the circuit then looked as shown in Fig. 8.

After making some input sensitivity adjustments to the oscilloscope that yielded images on the screen such as those in Table I (e) the TA said

TA:Now! Now it looks right. [Referring to what was seen on the oscilloscope.]

Table I (e) shows the oscilloscope indicating a square signal from the function generator on channel 2, and a characteristic charging and discharging curve from the capacitor on channel 1 . The students could finally get on with their measurements.

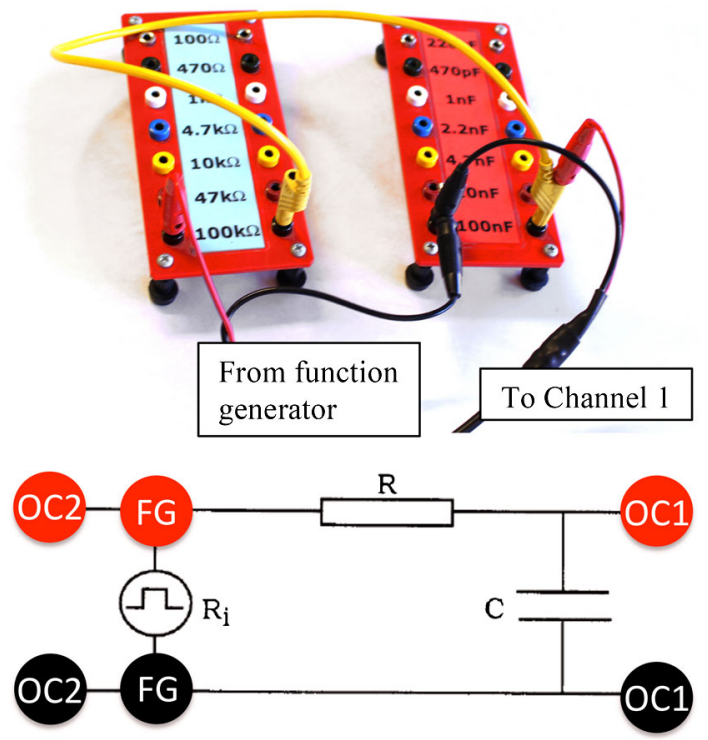

FIG. 8. A pictorial and a diagrammatic representation of the students' circuit after the TA's second intervention. Both "grounding ends" of the cables were then connected to the same (equivalent) point in the circuit. FG refers to the function generator and $\mathrm{OC} 1$ and $\mathrm{OC} 2$ refer to the oscilloscope's channel 1 and channel 2, respectively.

\section{GENERAL DISCUSSION AND EDUCATIONAL IMPLICATIONS}

Previous research has shown that students often experience difficulties interpreting and working with representations. In this article we have emphasized the teaching and learning challenges arising from the (increasingly) rationalized representations commonly used in physics education contexts. The vignette illustrates important aspects of these challenges. As was pointed out in Sec. III, A the rationalization of representations creates learning challenges for students in the form of ambiguous content. We argue that physics representations are "optimized" in the sense that the visual detail that they provide gets reduced to what physicists consider to be sufficient detail. For example, in our illustration the circuit diagram does not explicate any common ground. However, experienced users should be able to easily determine how it should be dealt with from the given context. While in this way rationalization sometimes makes a representation adaptable to a wider range of situations, in other cases its primary function is to further the economy of communication. For example, a reference to Einstein's summation convention would be sufficient for physicists to know the form of summation that is intended. Thus, in both of these instances, it is only as physicists have learned to take certain aspects of a representation for granted that these aspects then get rationalized away. This is something that needs to be taken into account when aiming to create optimal physics learning experiences.

To summarize, we argue that

- unpacking representations is a vital aspect of coming to appreciate the disciplinary affordances of representations-of attaining a more comprehensive access to the disciplinary knowledge,

- unpacking may need to take place through the use of multiple representations, since different representations have different disciplinary affordances, and,

- procedural knowledge should not be taken to subsume conceptual knowledge about the underlying physics.

While this article has made a theoretical argument about the rationalizations in physics representations that lead to important physics aspects not being initially discernible to students, a question remains regarding what approach teachers can take towards thinking about and addressing the learning challenges that arise from students having to face the partiality of such representations. The answer is not straightforward.

As we have pointed out, the rationalization of representations can be seen to be manifested in both teaching and learning challenges. For example, this could mean that teachers and students interpret representations differently. In our vignette this is illustrated by the students and the TA having somewhat different ideas of what is intended by the given representation (i.e., the circuit diagram). One way to approach the students' difficulty in appropriately interpreting the circuit diagram might be to say that the appropriate 
connection of cables is simply a matter of trial and error ("if it matters"- as one of the students in our example initially said). A more powerful approach might be to unpack the representation in order for the students to attain a conceptual understanding of the physics that could guide the appropriate connection.

In order to help students to discern what aspects are important in a physics context, we propose the educational need for unpacking representations be viewed as a joint teacher-student task. This task is about "coming to discern an aspect within the whole and relating it to other aspects, thus lending greater cohesion and detail to the phenomenon as a whole" [70] (p. 275). This would also entail "bringing certain aspects of [a] phenomenon, situation or construct to the fore while allowing other aspects to recede into the background" [70] (pp. 275-276).

What could this mean concretely for physics instruction? Using our vignette from the physics student laboratory as an example, we argue that a discussion of the following kind of questions would be necessary:

- What are the implications of the shared reference potential (grounding) of the equipment?

- How does the color coding of the plugs relate to the shield and the central conductor in the coaxial cableand to the reference potential of the equipment?

- What is the role of the resistor in the circuit?

- Why is a square wave output of the function generator needed?

- What is the relationship between the voltage input from the function generator and the voltage output across the capacitor?

- How should the image on the oscilloscope screen be interpreted?

- What is the role of the high internal resistance of the oscilloscope?

- How can the notion of a "current going through the capacitor" [41] (p. 1129; 1188) be unpacked for students?

We propose that physics teachers should "interrogate" the representations that they use by asking two questions:

(1) What inferred information (even if seemingly trivial) do the students need to learn to see in order to interpret a given representation in an appropriate, disciplinary manner for the given context of learning?

(2) How aware are the students of this inferred information, and will they be able to effectively and appropriately work with this representation?

We believe that by asking these questions physics teachers can start to develop fruitful ways to unpack the representations they use in their teaching for their students.

In summary, students need help to become aware of the critical physics aspects of a particular "phenomenon, situation or construct" [70] (p. 275). These aspects have often been rationalized out of the representations that we use in physics and as such they too easily get taken for granted. In order to gain access to these aspects of disciplinary knowledge, students need help with the unpacking of representations that can potentially provide this access.

In essence, the educational experience should allow students to work with representations in order to "discover" their disciplinary affordances. Teachers need to collaborate on creating lists of critical physics aspects, such as the illustrative list given above for the circuit diagram example. Equipped with such a list, teachers would need to find out if their students have become aware of these aspects-in other words, if they have come to appreciate the disciplinary affordances of the representations that are being used.

\section{FUTURE RESEARCH}

We suggest that the theoretical proposal that we have made in this article about rationalized representations as powerful communicative resources for physics while, simultaneously, constituting both learning challenges and teaching challenges, has the potential to provide a theoretical framing for existing research based instructional methods, such as Ranking tasks [71,72], Tutorials [73], Active Learning [74], and Peer Instruction [75]. In our view, the power of these highly regarded methods can be seen to stem from their opening up of a space in which the disciplinary affordances of physics representations can be unpacked and disambiguated. As such, this paper also provides a theoretical framing for the development of new instructional strategies.

Our conceptual framework could be used to revitalize the field of scholarship of teaching and learning (see, for example, [76] for a historical overview). Here, one can envisage teachers sharing their experiences of challenges for teaching and learning and discussing them in terms of aspects that have been rationalized away in the representations that are commonly used in teaching.

Another area of future research is related to the development of student meta-representational competence (MRC) [51], which could be an important complement to unpacking as a way for students to come to appreciate the disciplinary affordances of representations. MRC is defined as the "invention, critique, and understanding principles of operation" of representations [52] (p. 299). By practicing these skills in class, students could come to better appreciate the importance of rationalization of representations for powerful communication (see, for example, [77]). Further work is needed to explore the complementary roles of these approaches.

Most importantly, we argue that further empirical research is needed in order to explore and document three interconnected questions:

(1) What are the disciplinary affordances of the representations that are commonly used in areas of physics where students appear to struggle? 
(2) In what ways might the individual disciplinary affordances of these representations be unpacked for students?

(3) What is the critical constellation of representations $[2,78]$ that offers students the collective disciplinary affordance [16] needed for appropriate knowledge construction in these areas?

We believe that going forward, the theoretical proposal that we have presented, and further empirical research to address these three questions, have the distinct potential to enhance our understanding of teaching and learning in undergraduate physics.

\section{ACKNOWLEDGEMENTS}

We would like to thank the TA and the participating students. We thank Patrik Fredlund for help with images. We also thank the referees for their valuable input. Funding from the Swedish Research Council is gratefully acknowledged.

\section{APPENDIX THE LABORATORY INSTRUCTION FOR THIS PART OF THE LABORATORY EXERCISE}

Charging and discharging process in an $R C$ circuit using an oscilloscope.-

The purpose of the exercise below is to

- Experimentally [study the] charging and discharging process of a capacitance using an oscilloscope.

More rapid charging and discharging processes are best studied using the oscilloscope. Instead of a manual switch we then use a square wave generator, which gives a signal of the type $几 几 \neg$ of variable frequency. Note that the generator is called $\mathrm{R}_{\mathrm{i}}$ in Fig. 2, referring to the generator's "internal impedance."

Preparations.-

Assume that the square generator gives you a voltage between 0 and $5 \mathrm{~V}$. Draw in a diagram $\mathrm{U}(\mathrm{t})$ how you expect the voltages $\mathrm{U}_{2}(\mathrm{t})$ and $\mathrm{U}_{1}(\mathrm{t})=\mathrm{U}_{\mathrm{C}}(\mathrm{t})$ will look.

(a) Connect an $R C$ circuit to the square wave generator according to Fig. 2. Use component boards with resistors and capacitors to be able to choose different values of $R$ and $C$. Choose appropriate frequencies and appropriate $R$ and $C$ to be able to follow the whole charging and discharging process for a few different values of $R$ and $C$.

(b) The half time, in other words the time it takes for the capacitor voltage in an $R C$ circuit to decrease to its half value during discharging, is given by $T_{1 / 2}=\ln 2 \cdot \mathrm{RC}=\ln 2 \cdot \tau$, where $\tau$ is the time constant of the circuit. Measure the half time using the oscilloscope for a few different values of the time constant and compare with the theoretical value. Note that in this experiment the generator's out resistance $R_{i}$ $(50 \Omega)$ and the oscilloscope's in resistance $(\sim 1 \mathrm{M} \Omega)$ are part of the circuit. Choose $R$ appropriately so that the effect of these can be neglected.

Assessment.-

$\mathrm{T}_{1 / 2 \text { theoretical }}$.
[1] A. Van Heuvelen, Learning to think like a physicist: A review of research-based instructional strategies, Am. J. Phys. 59, 891 (1991).

[2] J. Airey and C. Linder, A disciplinary discourse perspective on university science learning: Achieving fluency in a critical constellation of modes, J. Res. Sci. Teach. 46, 27 (2009).

[3] T. Van Leeuwen, Introducing Social Semiotics (Routledge, New York, 2005).

[4] G. Kress, Literacy in the New Media Age (Routledge, London, 2003).

[5] M. A. K. Halliday, in Writing Science: Literacy and Discursive Power, edited by M. A. K. Halliday and J. R. Martin (The Falmer Press, London, 1993), pp. 117-136.

[6] D. Rosengrant, E. Etkina, and A. Van Heuvelen, An overview of recent research on multiple representations, AIP Conf. Proc. 883, 149 (2007).

[7] D. Rosengrant, A. Van Heuvelen, and E. Etkina, Do students use and understand free-body diagrams?, Phys. Rev. ST Phys. Educ. Res. 5, 010108 (2009).
[8] A. Van Heuvelen and X. Zou, Multiple representations of work-energy processes, Am. J. Phys. 69, 184 (2001).

[9] M. Enghag, J. Forsman, C. Linder, A. MacKinnon, and E. Moons, Using a disciplinary discourse lens to explore how representations afford meaning making in a typical wave physics course, Intl. J. Sci. Math. Educ. 11, 625 (2013).

[10] D. E. Meltzer, Relation between students' problem-solving performance and representational format, Am. J. Phys. 73, 463 (2005).

[11] T. Fredlund, J. Airey, and C. Linder, Exploring the role of physics representations: an illustrative example from students sharing knowledge about refraction, Eur. J. Phys. 33, 657 (2012).

[12] J. Airey, U. Eriksson, T. Fredlund, and C. Linder, On the disciplinary affordances of semiotic resources, http://hkr .diva-portal.org/smash/get/diva2:756217/FULLTEXT01 .pdf (2014).

[13] B. S. Ambrose, P. R. L. Heron, S. Vokos, and L. C. McDermott, Student understanding of light as an 
electromagnetic wave: Relating the formalism to physical phenomena, Am. J. Phys. 67, 891 (1999).

[14] L. C. McDermott, How we teach and how students learn-A mismatch?, Am. J. Phys. 61, 295 (1993).

[15] L. C. McDermott, in Toward a Scientific Practice of Science Education, edited by M. Gardner, J. G. Greeno, F. Reif, A. H. Schoenfeld, A. A. diSessa, and E. Stage (Lawrence Erlbaum, Hillsdale, NJ, 1990), pp. 3-30.

[16] C. Linder, Disciplinary discourse, representation, and appresentation in the teaching and learning of science, Eur. J. Sci. Math. Educ. 1, 43 (2013).

[17] U. Eriksson, C. Linder, J. Airey, and A. Redfors, Introducing the anatomy of disciplinary discernment: an example from astronomy, Eur. J. Sci. Math. Educ. 2, 167 (2014).

[18] D. T. Brookes and E. Etkina, Using conceptual metaphor and functional grammar to explore how language used in physics affects student learning, Phys. Rev. ST Phys. Educ. Res. 3, 010105 (2007).

[19] D. T. Brookes and E. Etkina, "Force," ontology, and language, Phys. Rev. ST Phys. Educ. Res. 5, 010110 (2009).

[20] T. J. Bing and E. F. Redish, Analyzing problem solving using math in physics: Epistemological framing via warrants, Phys. Rev. ST Phys. Educ. Res. 5, 020108 (2009).

[21] R. Karam, Framing the structural role of mathematics in physics lectures: a case study on electromagnetism, Phys. Rev. ST Phys. Educ. Res. 10, 010119 (2014).

[22] N.-L. Nguyen and D. E. Meltzer, Initial understanding of vector concepts among students in introductory physics courses, Am. J. Phys. 71, 630 (2003).

[23] P. Barniol and G. Zavala, Test of understanding of vectors: a reliable multiple-vector concept test, Phys. Rev. ST Phys. Educ. Res. 10, 010121 (2014).

[24] R. Duval, A cognitive analysis of problems of comprehension in a learning of mathematics, Educational Studies Math. 61, 103 (2006).

[25] R. Duval, Commentary: linking epistemology and semiocognitive modeling in visualization, DZM Math. Educ. 46, 159 (2014).

[26] J. L. Lemke, in Reading Science: Critical and Functional Perspectives on Discourses of Science, edited by J.R. Martin and M. Veel (Routledge, London, 1998), pp. 87-114.

[27] S. Ainsworth, DeFT: A conceptual framework for considering learning with multiple representations, Learn. Instr. 16, 183 (2006).

[28] S. Ainsworth, The functions of multiple representations, Comput. Educ. 33, 131 (1999).

[29] A. Einstein, Die Grundlage der allgemeinen Relativitätstheorie, Ann. Phys. (Berlin) 354, 769 (1916).

[30] A. Einstein, in The Principle of Relativity, edited by H. A. Lorentz, A. Einstein, H. Minkowski, and H. Weyl (Dover Publications, New York, 1952), pp. 111-164.

[31] J. L. Lemke, Talking Science (Ablex Publishing, Norwood, NJ, 1990).

[32] J. L. Lemke, Textual Politics: Discourse and Social Dynamics (Taylor \& Francis, Oxon, 1995).

[33] K. L. O'Halloran, Mathematical Discourse: Language, Symbolism and Visual Images (Continuum, London, 2005).
[34] J. Airey, Representations in Undergraduate Physics (Docent lecture, Ångström Laboratory, 9 June, 2014).

[35] J. R. Martin and M. Veel, Reading Science: Critical and Functional Perspectives on Discourses of Science (Routledge, London, 1998).

[36] M. A. K. Halliday and J. R. Martin, Writing Science: Literacy and Discursive Power (Falmer Press, U.K., 1993).

[37] M. A. K. Halliday, The Language of Science (Continuum, London, 2004).

[38] M. A. K. Halliday, in Reading Science: Critical and Functional Perspectives on Discourses of Science, edited by J. R. Martin and R. Veel (Routledge, London, 1998), pp. 185-236.

[39] P. D. Klein and L. Unsworth, The logogenesis of writing to learn: a systemic functional perspective, Ling. Educ. 26, 1 (2014).

[40] M. A. K. Halliday and C. M. I. M. Matthiessen, An Introduction to Functional Grammar (Hodder Education, London, 2004).

[41] H. D. Young and R. A. Freedman, University Physics with Modern Physics (Pearson, San Francisco, 2004), 11th ed.

[42] F. Nicoud, Conservative high-order finite-difference schemes for low-mach number flows, J. Comput. Phys. 158, 71 (2000).

[43] M. A. K. Halliday and C. M. I. M. Matthiessen, Construing Experience through Meaning (Cassell, New York, 1999).

[44] D. T. Brookes, Ph.D. thesis, The State University of New Jersey, 2006.

[45] J. S. Bruner, The Process of Education (Harvard University Press, Cambridge, 1960).

[46] A. B. Arons, Student patterns of thinking and reasoning, Phys. Teach. 21, 576 (1983).

[47] M. A. K. Halliday, in Writing Science: Literacy and Discursive Power, edited by M. A. K. Halliday and J. R. Martin (The Falmer Press, London, 1993), pp. 59-75.

[48] S. Tobias, Peer perspectives: On the teaching of science, Change 18, 36 (1986).

[49] A. Linder, J. Airey, N. Mayaba, and P. Webb, Fostering disciplinary literacy? South African physics lecturers' educational responses to their students' lack of representational competence, African J. Res. Math., Sci. Tech. (AJRMSTE) 18, 242 (2014).

[50] A. Northedge, in Learning for Life in the 21st Century, edited by G. Wells and G. Claxton (Blackwell Publishing, Oxford, 2002), pp. 252-264.

[51] A. A. diSessa and B. L. Sherin, Meta-representation: an introduction, J. Math. Behav. 19, 385 (2000).

[52] A. A. diSessa, Metarepresentation: Native competence and targets for instruction, Cognit. Instr. 22, 293 (2004).

[53] T. Fredlund, Licentiate thesis, Uppsala University, 2013.

[54] J. R. Martin, Embedded literacy: knowledge as meaning, Ling. Educ. 24, 23 (2013).

[55] R. P. Feynman, R. Leighton, and M. Sands, The Feynman Lectures on Physics (Basic Books, New York, 2010).

[56] L. C. McDermott and P. S. Shaffer, Research as a guide for curriculum development: An example from introductory electricity. Part I: Investigation of student understanding, Am. J. Phys. 60, 994 (1992).

[57] P. S. Shaffer and L. C. McDermott, Research as a guide for curriculum development: An example from introductory 
electricity. Part II: Design of instructional strategies, Am. J. Phys. 60, 1003 (1992).

[58] M. R. Stetzer, P. van Kampen, P. S. Shaffer, and L. C. McDermott, New insights into student understanding of complete circuits and the conservation of current, Am. J. Phys. 81, 134 (2013).

[59] N. Entwistle, J. Nisbet, and A. Bromage, Teachinglearning environments and student learning in electronic engineering, http://www.etl.tla.ed.ac.uk//docs/Brugge2004 .pdf (2004).

[60] A.-K. Carstensen and J. Bernhard, Student learning in an electric ciruit theory course: critical aspects and task design, Eur. J. Eng. Educ. 34, 393 (2009).

[61] We believe that in this process the addition of these colored dots is an unpacking that creates a new representation that could improve the learning about circuit connections in a student laboratory setting.

[62] C. Heath, J. Hindmarsch, and P. Luff, Video in Qualitative Research (SAGE Publications, London, 2010).

[63] O. Lindwall and G. Lymer, The dark matter of lab work: illuminating the negotiation of disciplined perception in mechanics, J. Learn. Sci. 17, 180 (2008).

[64] R.E. Scherr, Gesture analysis for physics education researchers, Phys. Rev. ST Phys. Educ. Res. 4, 010101 (2008).

[65] D. A. Rehn, E. B. Moore, N. S. Podolefsky, and N. D. Finkelstein, Tools for high-tech tool use: A framework and heuristics for using interactive simulations, J. Teach. Learn. Technol. 2, 31 (2013).

[66] K.-S. Tang, C. Delgado, and E. Birr Moje, An integrative framework for the analysis of multiple and multimodal representations for meaning-making in science education, Sci. Educ. 98, 305 (2014).

[67] N. S. Podolefsky and N. D. Finkelstein, Analogical scaffolding and the learning of abstract ideas in physics: empirical studies, Phys. Rev. ST Phys. Educ. Res. 3, 020104 (2007).

[68] J. Bezemer and D. Mavers, Multimodal transcription as academic practice: a social semiotic perspective, Intl. J. Soc. Res. Methodology 14, 191 (2011).

[69] A. Baldry and P. J. Thibault, Multimodal Transcription and Text Analysis (Equinox Publishing, London, 2006).

[70] Å. Ingerman, C. Linder, and D. Marshall, The learners' experience of variation: following students' threads of learning physics in computer sessions, Instr. Sci. 37, 273 (2009).

[71] S. Andersson, Rangordningsövningar $i$ naturvetenskap: en inspirationsrapport om en studentaktiv undervisningsmetod (Uppsala University, Uppsala, 2011).

[72] D. P. Maloney, Ranking tasks: a new type of test item, J. Coll. Sci. Teach. 16, 510 (1987).

[73] L. C. McDermott and P.S. Shaffer, Tutorials in Introductory Physics (Prentice-Hall, Upper Saddle River, NJ, 2002).

[74] A. Van Heuvelen and E. Etkina, The Physics Active Learning Guide (Addison-Wesley, San Fransisco, 2006).

[75] C. H. Crouch and E. Mazur, Peer Instruction: Ten years of experience and results, Am. J. Phys., 69, 970 (2001).

[76] K. McKinney, Enhancing Learning through the Scholarship of Teaching and Learning: The Challenges and Joys of Juggling (Anker Publishing Company, Bolton, MA, 2007).

[77] R. Lehrer and L. Schauble, in Instructional Explanations in the Disciplines, edited by M. K. Stein and L. Kucan (Springer, US, 2010) doi: , pp. 9-22.

[78] J. Airey, Science, language and literacy. Case studies of learning in Swedish university physics, Ph. D. thesis, Uppsala University, Uppsala, 2006 (unpublished), http://www.diva-portal.org/smash/record.jsf?pid=diva2\% 3A173193\&dswid=-4725. 